\title{
Norms of Cooperation, Trust, Altruism, and Fairness: Evidence from Lab Experiments on Pakistani Students
}

\section{Theresa Thompson Chaudhry* and Misha Saleem**}

\begin{abstract}
A rich area of economic research focuses on the role of controlled experiments to understand interactions between agents and agents' own deepseeded preferences as they pertain to pro-social behavior. Four of the most common games - the prisoner's dilemma, and the trust, ultimatum, and dictator games-have been used both in laboratory and field settings, and with student and nonstudent participants. Cardenas and Carpenter (2008) have compiled evidence for these four games that has been collected from behavioral experiments conducted in the US and a number of developing countries. In this paper, we wish to add to the existing evidence by presenting the results of lab experiments carried out on a population of economics students at a university in Lahore.
\end{abstract}

Keywords: Behavioral Environment, Games, Lahore, Pakistan.

\section{JEL Classification: C73, C93.}

\section{Introduction}

According to the New Institutional Economics outlined by North (1990), institutions are the "humanly devised constraints that shape human interaction;" in other words, they are the rules of the game in society, constraining behavior and shaping incentives. In the New Institutional Economics literature, institutions affect transaction (exchange) costs and transformation (production) costs, thus impacting economic performance (North, 1990). Institutions may be formal or informal. Examples of formal institutions include federal and provincial statutes, common law, constitutions, and written contracts. Informal constraints can be broadly described as customs, norms, conventions of behavior, morals, and generally accepted codes of conduct.

\footnotetext{
${ }^{*}$ Associate Professor, Department of Economics, Lahore School of Economics.

${ }^{* *}$ Teaching Fellow, Department of Economics, Lahore School of Economics.
} 
Institutions generally change slowly. So even if formal institutions change suddenly (revolution), customs and other informal constraints do not. Therefore, history is important, leading to the notion of "path dependence" in the New Institutional Economics; where a society has been (in terms of its economic and political systems) affects how it changes, and the opportunities for what it becomes in the future. Also implicit in the notion of path dependence is the recognition that societies can diverge on to different paths and end up in different circumstances in terms of the presiding political system, economic relations, and norms of behavior. The importance of both formal and informal institutions on economic development has been demonstrated empirically (Acemoglu et al., 2001; Knack \& Keefer, 1997).

The relationship between formal and informal institutions is a complex issue, which we cannot fully explore here. However, it is thought that, in developing countries, where certain formal institutions are weak, informal ones may take their place. (Informal institutions are often more permanent and slow changing than formal ones, playing a prominent role in the path dependence hypothesis.) These include prosocial norms that contribute to the social capital of a society, including cooperation, trust and reciprocity, altruism, and fairness, which are the focus of this paper. Cooperation can help enforce agreements when there is an incentive to renege-thereby substituting for contract enforcementand contribute to public goods to fill in for government provision when public execution is weak. Trust and reciprocity help build and maintain relationships (both business and otherwise) and develop informal insurance mechanisms. Altruism aids in the protection of the most vulnerable and can help substitute for social safety nets. Norms of fairness help adjudicate local disputes, which can be particularly useful when formal enforcement is ineffective.

A number of papers have used evidence from experiments conducted on subjects either in the laboratory or in the field to measure these pro-social norms. Cardenas and Carpenter (2008) compiled the results across a number of countries in order to draw some comparisons between developed and developing countries. Experimental evidence from Pakistan is scarce; therefore this paper aims to contribute to the cross-country evidence on lab experiments regarding social preferences. We focus on four of the experiments covered by Cardenas and Carpenter: (i) the prisoner's dilemma (norms of cooperation), (ii) the dictator game (altruism), (iii) the ultimatum game (fairness), and (iv) the trust game (trust and reciprocity). In each of these games, there is a clear theoretical 
prediction for an individual's behavior from noncooperative game theory, based on the assumption of rational payoff maximization. However, as will be discussed later, the harsh predictions of game theory are rarely borne out in actual play in either the field or the lab. The magnitude of the divergence from the predictions of theory is then interpreted as the extent of pro-social norms within the group.

The remainder of the paper proceeds as follows. Section 2 presents a review of the literature. Section 3 describes the rules of the four games. Section 4 describes the framework for the lab experiments performed. Section 5 presents our results based on the games played by Lahore-based students, and Section 6 concludes the study.

\section{Literature Review}

The literature on experimental economics focusing on understanding human behavior is quite extensive. The experiments carried out in this area of research have tried to explain norms of cooperation, fairness, altruism, and trust. Levitt and List (2006) broadly classify experiments explaining social preferences into two: (i) experiments carried outside the lab, and (ii) experiments carried inside the lab. Given the strengths and weaknesses of each approach, lab experiments are useful in providing qualitative insights as compared to field experiments, which might be more useful for quantitative analysis. Nevertheless, lab experiments appeal to economists as they provide ceteris paribus observations where the investigators can directly control the game's parameters, including budget sets, information sets, and available moves.

Much of the economic models and almost all of game theory begin with an assumption that individuals are both rational and selfish. Theoretically speaking, this would mean that individuals tend to defect, not cooperate, or free-ride in experimental games measuring cooperation. A large amount of experimental evidence however shows that often individuals choose actions that are not in their best interest. Such actions are commonly viewed as individuals' attempts to cooperate (Cooper et al 1996). In this regards, the prisoner's dilemma game (PD) and public goods games are two sets of games commonly played.

An abundance of literature has tried to explain when and why individuals cooperate in settings (such as finite repetitions of the PD game) where the prediction of the basic theoretical game is noncooperation. In this regard, Kreps et al (1982) has been amongst the first to 
demonstrate that cooperation can be reached in experiments involving finite repetitions of the prisoner's dilemma game. In other words individuals might be observed to not play "defect", even though "defect" is the unique Nash equilibrium at each stage of the finitely repeated PD with complete information. The authors prove how reputation effects due to incomplete information about one or both players' behavior can result in cooperation in equilibrium in early stages of the game. The authors build two main models and show that even a small belief about the plausibility of such behavior by the opposing player can make it rational for an individual to himself cooperate. These are that either i) the opponent is playing a tit-for-tat strategy (i.e. choosing to cooperate, following cooperative behavior by the opponent), or that ii) mutual cooperation may sufficiently raise the utility of the other player.

Andreoni and Miller (1993) test the model posed by Kreps et al (1982) to evaluate its predictive power by influencing the participants' beliefs regarding their partners' intentions. In addition to the reputation building, the authors also look at a model based on altruism (also called the warm-glow hypothesis) to explain cooperation in PD. While Kreps et al (1982) only allowed for beliefs regarding altruism in the subjects, the authors in this paper allow altruistic participants to exist in reality. Randomly assigning students at the University of Wisconsin to lab computers, the experiment was run under four different treatments. These treatments were "partners" (anonymous pairings of students rematched in each period allowing for reputation building), "strangers" (random pairing in each round/iteration to avoid any reputation building), "Computer50" (group instructions same as that for partners with an announced probability that the subjects play against a computer which would play tit-for-tat strategy) and "Computer0" (same as Computer50 except that the probability of playing with the computer reduced to 0.1 percent). The resultswere consistent with the reputation building model (increasing an individual's beliefs about the probability that their opponent is altruistic increases reputation building) but also show that a fraction of the students playing actually appeared to be altruistic (consistent with warm-glow hypothesis that people get additional utility from mutual cooperation).

Cooper et al (1996) makes a similar comparison between one-shot games and finitely repeated games by conducting experiments with undergraduate and graduate students of University of Iowa. The authors identify reputation building effects and altruistic players amongst the sample, but neither explanation alone can explain the observed levels of 
cooperation. Compared to zero cooperation predicted by standard economic theory in sequential one-shot games, the authors showed that cooperation increases as players interact for a finite number of plays. In the one-shot prisoner dilemma games, the cooperation rates were greater than 20 percent, with cooperation rates starting out higher in the early periods of play and then tapering off. They identify a proportion of altruistic players within the sample at approximately $12-13$ percent of the subjects.

Another paper by Frank et al (1993) conduct a prisoner's dilemma experiment through questionnaires involving both economics students and non-economics students to examine whether studying economics negatively impacts an individual's natural inclination toward cooperative behavior. The results showed a higher defection rate amongst economic majors of nearly $2 / 3$ as compared to non-majors which had a defection rate of less than 40 percent. The authors also regress the cooperation rates on controls to test for effects of gender, age or experimental condition. Defection rates were higher among male subjects, and were negatively related to years of education.

Bohnet and Frey (1993) show how identification amongst the subjects (even without communication) also induces a higher level of cooperation, as compared to anonymous treatments. The results showed that even silent identification increased cooperation (by 11 percentage points) as compared to the anonymous setting, and communication further boosted the cooperation rate to an astonishing 78 percent.

Hemesath and Pomponio (1998) on the other hand is an attempt to examine how cooperative behavior varies across cultures. Experimenting with Chinese undergraduates and American college students, using random matching of participants, the authors found a 25 percent cooperation rate in the American students as compared to a 54 percent cooperation level amongst Chinese students.

Many economists recognize the importance of trust in economic transactions, efficiency, social capital, cooperation within firms, and its link with economic indicators such as the gross domestic product (GDP) growth rate and investment relative to GDP (Fukuyama, 1995; Knack \& Keefer, 1997; Kramer \& Tyler, 1996; Putnam, 1995, 2000; Zak \& Knack, 2001). Often cited is Knack and Keefer (1997), where the authors use trust indicators from World Values Surveys from 29 economies, and suggest that formal institutions for the provision of better mechanisms to fulfill contracts are more important in economies where interpersonal trust is 
low. They show that trust norms are stronger in nations with less income inequality and higher literacy rates. The authors show, for example, that an increase of one standard deviation in country-level trust predicts an increase in economic growth of more than one half of a standard deviation.

On an individual level, Berg et al. (1995) identify an experimental design in an investment setting with complete anonymity to show that trust can be used for mutual gain. The double blind procedure's intent is to rule out reputation effects in repeated interactions, contractual precommitments, and potential punishment threats. The authors show that, 55 out of 60 times, students sent a positive amount of money. Typically in trust games, first players (trustors) lose money or break even, receiving back the same or less than what they passed on to the trustee, even though the amount they sent was tripled by the experimenter.

Burks et al. (2003) use a modified trust game to show that informing each student of their dual roles as both trustor and trustee leads to a significant reduction in both trust and reciprocity behaviors. Where many economists believe that trustees return money conditional on the generosity of the trustor's intentions or behavior (Cox \& Friedman, 2002; Rabin, 1993), some studies have had difficulty identifying this demand by second movers on the trustor's behavior (Ashraf et al., 2006). Ashraf et al. conduct four experimental sessions: two trust (investment) and two dictator game experiments among a heterogeneous sample of male and female college students in Russia, South Africa, and the US. Controlling for risk preferences and expectations of return, the authors show that trust is not just related to expectations of return but also to "unconditional kindness" especially in the case of Russia and South Africa as opposed to the US where reciprocity is more relevant. While over 90 percent of trustors send money, only a minority expects to make a positive return on its investment, stressing the role of kindness.

Many studies have used trust games to measure differences in social preferences due to demographic differences among individuals. Buchan et al. (2003) find that women are more trustworthy and less trusting than men by running investment (trust) games with students in the US. Buchan et al. (2006) run an investment game with students in China, Korea, Japan, and the US to find that differences in trust, reciprocity, and altruism vary across country of origin, cultural orientation, and social distance among subjects. The study also shows that Chinese participants are more trusting and trustworthy than their counterparts from other countries. Fehr and List (2004) compare the 
behavior of Costa Rican students and chief executive officers, and find the familiar result of lower pro-social behavior (trust and trustworthiness) among the student group.

Glaeser (2000) compares measures of trust and reciprocity in surveys with investment (trust) games (similar to those in Berg et al., 1995) played with Harvard undergraduates. The study shows that, if subjects are paired with counterparts from a different race or nationality, they tend to return less money than they receive. Lazzarini et al. (2004) replicate Glaeser's study using a sample of Brazilian students. They show that, in comparison to the Glaeser study where 42.6 percent of students showed trust, only 21.7 percent (measured on a World Value Survey scale) of the Brazilian students surveyed trusted their counterparts; despite this, the return ratio of 80 percent was not significantly different from that of Glaeser. Both Glaeser (2000) and Lazzarini et al. (2004) find that surveyed measures of trust are not good indicators of trusting behavior, but rather they indicate trustworthiness.

Experimenters often run dictator games ${ }^{1}$ in addition to trust games to see what motivates first-movers to transfer their endowment without expecting a return, which is also interpreted as altruism. Carter and Castillo (2002) try to differentiate trust and reciprocity from altruism by conducting three games (where subjects are given the roles of dictator, trustor, or trustee) in 14 South African communities, spanning both urban and rural settings. The authors prove that trust norms are stronger in communities that expect reciprocity in return. On average, trustors sent 53 percent of their endowment, and the average share returned was 38 percent. Over 70 percent of subjects sent an amount between 40 and 60 percent, where the percentage varied across communities. On average, the share sent in the dictator game was found to be 42 percent, showing high levels of altruism.

As already mentioned, Ashraf et al. (2005) recognize that some first movers may show trust as a general act of kindness as opposed to being in expectation of reciprocity. (Other first movers have different motivations, and may view the trust game as an investment game with uncertainty.) Such acts of unconditional kindness could be due to social preferences such as altruism. In the dictator and triple dictator games run by the authors, only 14 percent of first movers did not send anything, indicating a lack

\footnotetext{
${ }^{1}$ This is done to observe trustors' behavior when no reciprocity is expected. Kahneman et al. (1986) experimented with dictator games for the first time and found that three quarters of the subjects who played opted for an equal split with their counterparts.
} 
selfish behavior by the majority of players. The returns made by trustees are explained better by altruism (or unconditional kindness) than reciprocity. The mean allocation in all three countries (the US, Russia, and South Africa) is close to the standard result of about 20 percent (Camerer, 2003). Holm and Danielson (2005) carried out both a dictator game and a trust game among students in Sweden and Tanzania. They found a strong relationship between the proportion of amount returned in the trust game and contributions in the dictator game. Trustors sent similar amounts on average in both countries (just over 50 percent of the endowment). Trustees in both countries then returned similar amounts of the funds received (a little more than a third). The study rules out pure generosity as the intention of the player in the trustor role. The trustee's behavior, however, is found to be motivated by both reciprocity and charity in both countries.

Carpenter et al. (2004) investigate the external validity of ultimatum and dictator games by conducting a field experiment among students at Middlebury College (an elite institution), nontraditional students at a community college in the US state of Kansas, and employees at a distribution center also in Kansas. The authors examine the effect of social framing ${ }^{2}$ on the behavior of subjects at the Kansas community college and distribution center by controlling for demographic variables, and the effect of demographics on students at the Kansas community college and Middlebury College by controlling social framing effects. The workers at the Kansas distribution center and college made high offers in both games as compared to Middlebury students. The Kansas college students proposed less generous amounts than the distribution center workers, signaling the importance of social framing. This shows that altruistic norms and preference for sharing gains with co-workers are stronger within a workplace than in a classroom. In the ultimatum game, all offers made by the Kansas community college students were for 50-50 splits, while over 70 percent of the workers at the distribution center also offered the 50-50 split. At Middlebury, less than half the proposers made this offer.

Eckel and Grossman (1996) also show that subjects behave less generously toward anonymous counterparts in a dictator game. Hoffman et al. (1994) find that anonymity in dictator games via a double-blind procedure reduces the percentage of subjects (from 46 to 16 percent) that choose to donate 30 percent or more of their endowment. Additionally, the authors show that changing the instructions of the game significantly

2 "Subjects beliefs are influenced by the real-life social context... by their relationship to the people they are playing against and to the experimenter and by the set of norms and habits that dominate the cultural life in the institution in which the experiment is carried out" (Carpenter et al., 2004). 
changes offers in both games. Carter and Irons (1991) carry out an ultimatum game among economics and non-economics students and find that the former behave more selfishly.

Henrich et al. (2001) conducted a large cross-sectional field experiment in 15 small-scale societies by carrying out ultimatum, dictator, and public good games. Their study concludes that behavioral differences across societies stem from differences in economic organization and the degree of integration with outside communities via markets. The authors find that the mean offer in their sample ranges from 26 to 58 percent. Individuals within a group follow strong sharing norms while those outside the group or community tend to be less generous. On a similar pattern, Henrich et al. (2006) conducted ultimatum and third-party punishment games (where a bystander can punish the dictator for low offers), proving that individual differences are less important than community differences. The study shows that while communities punished offers of less than half of the endowment, the willingness to punish was not uniform across communities. In Gowdy et al. (2003), first movers in a Nigerian village made similar average offers (of just over 40 percent) in both ultimatum and dictator games. In spite of dire poverty, high levels of altruism among the villagers are attributed to community-level characteristics (rather than differences among individuals) including religious beliefs, local norms of fairness and cooperation, and a high degree of face-to-face social interaction. Cameron (1999) carried out an ultimatum game with students in Indonesia and showed that while the behavior of the first mover does not change with an increase in real money stakes, the willingness to accept by the second mover or responder does respond positively.

Literature on Pakistani Subjects

Delavande and Zafar (2011) carried out trust and dictator games among a sample of university and madrassa (seminary) students in Pakistan to examine within- and across-group behavior, finding high levels of trust, trustworthiness, and altruism across and within all groups. Looking at the sample overall, nearly 43 percent of the endowment was given in the dictator games. In their modified trust game (where the trustor could pass all or nothing of their endowment), almost three quarters of the participants passed their endowment, with only 3 percent of trustees giving back nothing in return, resulting in return ratios that were significantly greater than 1 . Razzaque (2009) conducted ultimatum games focusing on the role of gender among students in Rawalakot and Lahore, Pakistan, and found first-round offers to be about 39 percent of 
the endowment. Despite the offers proposed by male and female players 1 to be nearly the same (male offers were marginally higher), the women's offers were rejected at significantly higher rates.

\section{Theoretical Descriptions of the Four Games}

In this section, we describe the rules of play for each of the four games played in the lab and the predictions for play, given by the Nash equilibrium, based on noncooperative game theory. These games include the prisoner's dilemma, the trust game, the dictator game, and the ultimatum game.

\section{The Prisoner's Dilemma}

The prisoner's dilemma is a one-period, simultaneous-move game, so each player does not observe the other player's action until the game is over. Player 1 has the possible moves "top" and "bottom," and player 2 has the choice between "left" and "right." The combination of the two players' moves determines the payoffs for each player. In each payoff box in Figure 1 (below), the first number refers to the payoff of player 1, and the second number gives the payoff to player 2. For example, if player 1 chooses "bottom" and player 2 chooses "left," player 1 and 2 receive $\$ 1.00$ and $\$ 0.00$, respectively.

Figure 1: The Prisoner's Dilemma

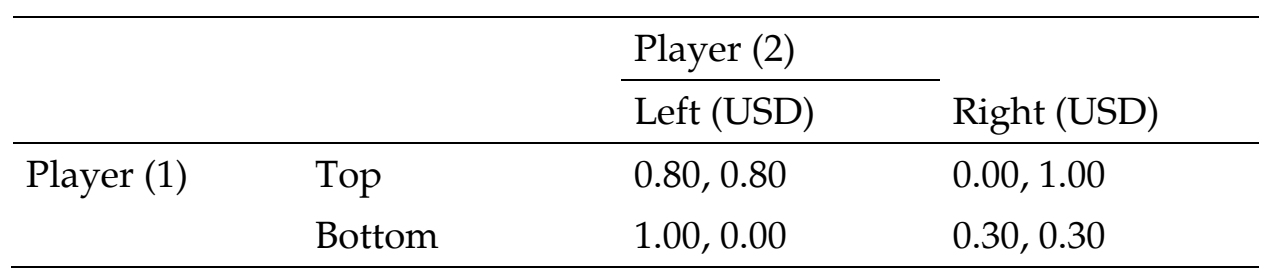

According to noncooperative game theory, player 1 should always choose "bottom" since "bottom" gives player 1 a higher payoff regardless of player 2's decision $(\$ 1.00>\$ 0.80, \$ 0.30>\$ 0.00)$; in other words, "bottom" is payoff-dominant. Likewise, "right" is the payoff-dominant move for player 2. Therefore, players 1 and 2 should rationally choose "bottom" and "right," resulting in a payoff of $\$ 0.30$ for each. However, the players would have jointly been better off had they cooperated and chosen "top" and "left" for payoffs of $\$ 0.80$ for each player. 
The "rational" (or purely self-interested) player would choose "right" and "bottom" (not cooperate) according to the predictions of game theory, i.e., the Nash equilibrium. However, when these games are put toward ordinary individuals, people's choices often differ from the stark predictions of theory. The share of players choosing "top" and "left" provide us a measure of cooperation.

\section{The Trust Game}

The trust game takes place over two periods. In period 1, player 1 (the "trustor") starts with an endowment of $\$ 10.00$ and decides on an amount " $\mathrm{D}$ " to pass to player 2 (the "trustee"). The experimenter triples the amount $\mathrm{D}$, so that player 2 receives 3D. If player 1 does not pass anything to player 2 , the game ends and player 1 keeps $\$ 10.00$, and player 2 gets $\$ 0.00$. If player 2 passes a positive amount, in the second stage player 2 observes 3D and decides on the share " $n$ " to pass back to player 1 out of the 3D they received. Payoffs to player 1 and player 2, respectively, at the end of the second stage are $\$ 10.00-D+3 \mathrm{Dn}$ and $\$ 3 \mathrm{D}(1-\mathrm{n})$. See Figure 2 for a depiction of the game.

According to noncooperative game theory, we should solve the game by backward induction, and start by predicting what player 2 will do in the second (last) stage. Rationally, player 2 would maximize payoffs by keeping the full amount, 3D, passed by player 1 and set $n=0$. Player 1 should anticipate this in stage 1 , and maximize payoffs by not sending any money, setting $\mathrm{D}=0$, because they know they will not receive anything back in the second stage.

\section{Figure 2: The Trust Game}

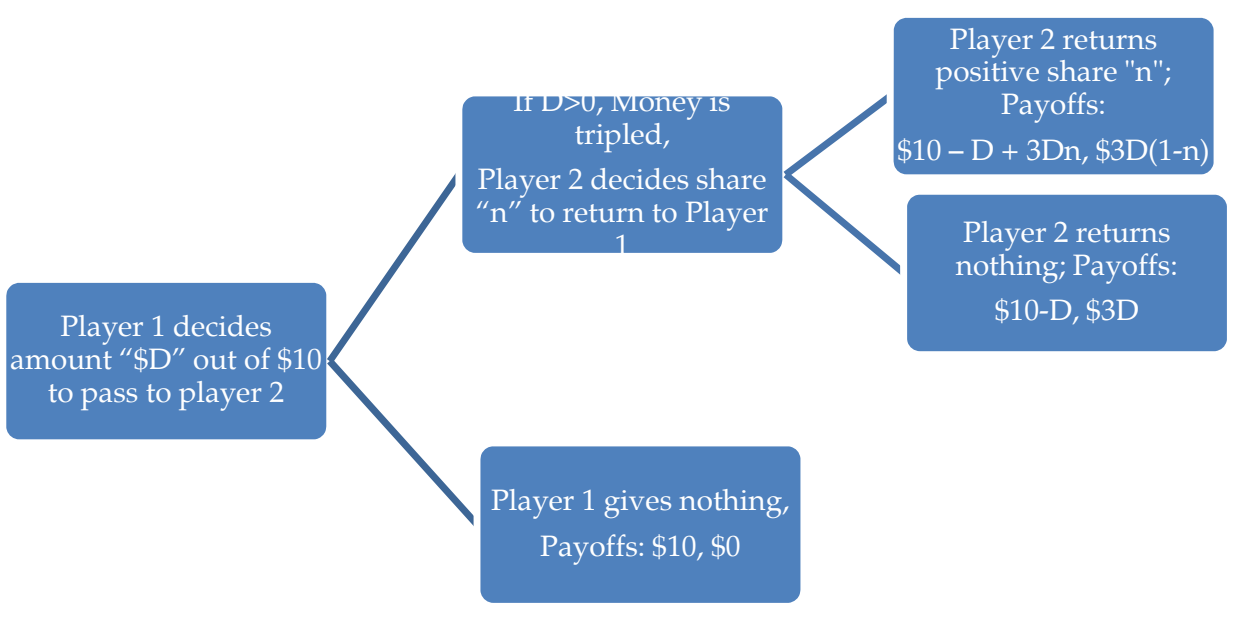


As described in the previous paragraph, in the Nash equilibrium, the "rational" player 1 would keep the entire endowment according to the predictions of game theory, predicting that player 2 would return nothing. However, when these games are put toward ordinary individuals, both players typically give positive amounts. The share returned by player 2 is a measure of "trustworthiness." The share given by player 1 is typically considered to be a combination of altruism and trust; if one is willing to make some strict assumptions about the additivity of preferences, one can subtract the measure of altruism calculated in the dictator game from the share proposed in the trust game to get a measure of "pure trust."

\section{The Dictator Game}

The dictator game is a simple one-period game. Player 1 decides on an amount " $\mathrm{D}$ " out of an endowment of $\$ 10$ to give to player 2. Player 2 has no move in this game, and the payoffs are $\$ 10-\mathrm{D}$ and $\mathrm{D}$, respectively, for players 1 and 2 (see Figure 3). Clearly, since the second player has no move, the payoff-maximizing player 1 would keep the entire endowment and set $\mathrm{D}=0$.

\section{Figure 3: The Dictator Game}

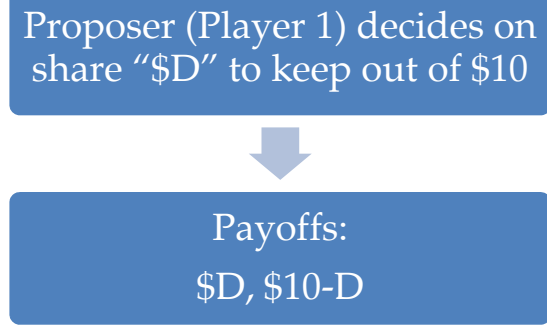

The "rational" proposer would keep the entire endowment according to the predictions of game theory. However, when these games are put toward ordinary individuals, the proposer (player 1) typically donates a positive amount, where the share given provides a measure of "altruism."

\section{The Ultimatum Game}

The ultimatum game is a two-period game. In stage 1, player 1 decides on an amount " $\mathrm{D}$ " out of a $\$ 10$-endowment to send to player 2 . In stage 2, player 2 observes player 1's offer and decides to accept or reject. 
If player 2 accepts, player 2 gets $\$ D$ and player 1 keeps $\$ 10-D$. If player 2 rejects the offer, both players get $\$ 0$. As in the trust game, in theory we should solve the game by first at player 2's options in the second stage. For player 2, any strictly positive $\mathrm{D}$ should be accepted because it gives a higher payoff than rejecting, which results in a payoff of 0 . If $D=0$, then player 2 should be indifferent between accepting and rejecting player 1's offer. If it is assumed that offers that make player 2 indifferent are accepted, then player 1 will maximize their own payoff by offering $D=0$ and the offer will be accepted by player 2 . If offers of $D=0$ are expected to be rejected, player 1 should offer the smallest $D$ such that $D>0$, ensuring acceptance by player 2 and maximizing player 1's payoff.

Figure 4: The Ultimatum Game

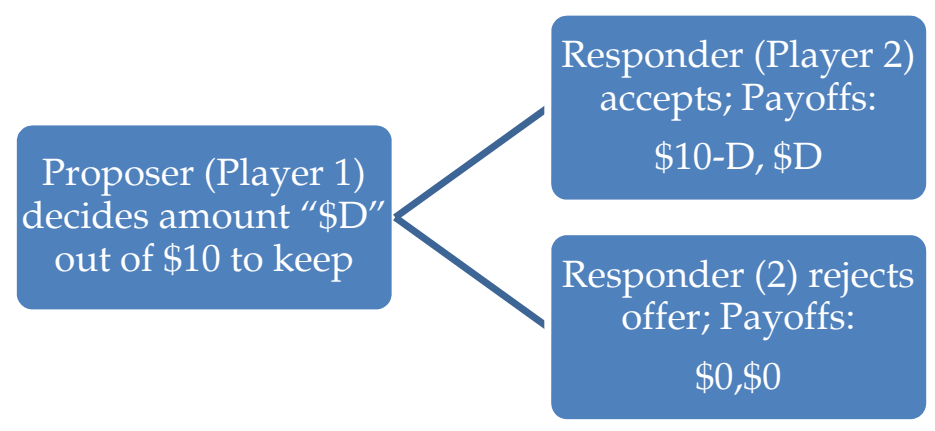

As we have seen, according to noncooperative game theory, the "rational" proposer would keep the entire endowment (or give the smallest positive amount), and the responder should accept. However, when these games are put toward ordinary individuals, responders often reject positive offers that are perceived as too small. The highest share rejected can be interpreted as a measure of "fairness."

\section{Description of Experimental Frame}

The games were conducted in the context of an intermediate microeconomics class in four different classes (or "sections") between 2009 and 2011. All students participating were economics majors. As the games were part of a classroom assignment, real money was not transacted. The games were played online using Charles Holt's Vecon Lab Experiment website (http:/ / veconlab.econ.virginia.edu/admin.htm).

In a particular session, there were between 24 and 40 students, all from the same section. The students in the same session know each other, 
and take most of their undergraduate coursework together. However, pairings for the games were randomly assigned, and in the vast majority of cases the students did not know exactly with whom they were paired. The pairing was fixed for all rounds of a particular game, but changed with each game played. Each student sat in front of a computer in a large computer lab. All students in the same session were simultaneously in the same computer lab. The decisions in the games took place in real time.

\section{Results of the Experiments}

In this section, we describe the results for each of the four games from the lab experimental sessions. We examine the behavior overall for all sessions, by round, by session, and breakdowns by gender.

\section{The Prisoner's Dilemma}

The experimental results for the prisoner's dilemma are given in Table 1. The mean cooperation in the first round was 35 percent. Women were found to be somewhat more cooperative than men when looking at all results across rounds (33 and 25 percent, respectively). There were also substantial differences across sessions, with mean cooperation ranging from 19 to 34 percent. There is also a clear pattern of learning across the rounds. Over one third cooperate in the first two rounds of play, with cooperation quickly dropping to around one quarter in rounds three through five.

Some results for the prisoner's dilemma games played with students across countries are provided in Table A1 in the annexure. Our results for Pakistan, focusing on the first round of results, which demonstrate the natural inclinations of the participants rather than learning or "gaming," indicate greater levels of cooperation at 35 percent than the US but lower levels than China and South Africa. While these results are limited, when combined with the results of other types of cooperation games, there is roughly an inverse relationship between cooperative behavior and economic development. This implies that cooperation can help to substitute for formal institutions. 
Table 1: Results of the Prisoner's Dilemma

\begin{tabular}{lcc}
\hline Subsample & Mean Cooperation & No. of Observations \\
\hline All & 0.28 & 700 \\
Women, men & $0.33,0.25$ & 318,382 \\
\hline Round 1 & 0.35 & 132 \\
Round 2 & 0.39 & 132 \\
Round 3 & 0.22 & 132 \\
Round 4 & 0.23 & 132 \\
Round 5 & 0.27 & 132 \\
\hline Section 1 & 0.19 & 200 \\
Section 2 & 0.36 & 240 \\
Section 3 & 0.24 & 120 \\
Section 4 & 0.34 & 140 \\
\hline
\end{tabular}

Source: Authors' calculations.

The Trust Game

The results from the experimental sessions for the trust game are presented in Tables $2 \mathrm{a}$ and $2 \mathrm{~b}$. Combining the results of all sessions, in the first round, trustors (player 1) sent 35 percent of their endowment, and trustees sent back just under a quarter of the tripled amount passed to them. On average, trustors lost money in all rounds, with a return ratio (amount received/sent) significantly less than 1. Over all rounds, women trustors sent less than men (23 and 33 percent of endowment, respectively) and also sent back less as second movers (21 versus 26 percent), displaying less trust and trustworthiness. Over the five rounds of play, the amount sent by the first player fell to 25 percent of the endowment. However, one might have expected it to fall more precipitously, given the consistently negative returns on the trustors' investments (Table 2a). 
Table 2a: Results of the Trust Game

\begin{tabular}{lcccc}
\hline Subsample & Fraction Sent & $\begin{array}{c}\text { Fraction Returned } \\
\text { (if Received +) }\end{array}$ & Return Ratio & $\begin{array}{c}\text { No. of } \\
\text { Observations }\end{array}$ \\
\hline All & 0.28 & 0.24 & 0.71 & 366 \\
Women, men & $0.23,0.33$ & $0.21,0.26$ & $0.64,0.78$ & 180,186 \\
\hline Round 1 & 0.35 & 0.24 & 0.73 & 63 \\
Round 2 & 0.33 & 0.22 & 0.66 & 61 \\
Round 3 & 0.27 & 0.23 & 0.70 & 61 \\
Round 4 & 0.22 & 0.26 & 0.79 & 61 \\
Round 5 & 0.25 & 0.24 & 0.71 & 61 \\
\hline Section 1 & 0.21 & 0.20 & 0.59 & 96 \\
Section 2 & 0.25 & 0.24 & 0.73 & 133 \\
Section 3 & 0.29 & 0.21 & 0.64 & 78 \\
Section 4 & 0.48 & 0.29 & 0.88 & 59 \\
\hline
\end{tabular}

Source: Authors' calculations.

In Table 2b, we can see that, in the first round, more than 90 percent of first-movers sent something to the second mover. Even though three quarters of second movers returned money in the first round, the return ratio (return on the investment) was low and the share of first movers that sent nothing jumped up in the second round.

There was a significant amount of variation across sessions. Section 1 was low-trust, with low amounts sent and low amounts returned. Section 4 , on the other hand, was relatively high-trust. In section 4, first movers sent 48 percent of endowments and returned 29 percent of the (tripled) amount they received. It was a smaller session and characterized by majorities of first movers sending money and second movers returning positive amounts (Table $2 \mathrm{~b}$ ). Nonetheless, the return ratio was less than 1 (signifying negative returns on the trust investment) even in this session. 
Table 2b: Results of the Trust Game (cont'd)

\begin{tabular}{lccc}
\hline Subsample & Share Send Nothing & $\begin{array}{c}\text { Share Return } \\
\text { Nothing (if } \\
\text { Received +) }\end{array}$ & $\begin{array}{c}\text { No. Of } \\
\text { Observations }\end{array}$ \\
\hline All & 0.29 & 0.28 & 366 \\
Women, men & $0.33,0.26$ & $0.29,0.27$ & 166,203 \\
\hline Round 1 & 0.08 & 0.26 & 63 \\
Round 2 & 0.23 & 0.34 & 61 \\
Round 3 & 0.39 & 0.22 & 61 \\
Round 4 & 0.38 & 0.18 & 61 \\
Round 5 & 0.31 & 0.31 & 61 \\
\hline Section 1 & 0.40 & 0.41 & 96 \\
Section 2 & 0.35 & 0.26 & 133 \\
Section 3 & 0.19 & 0.22 & 78 \\
Section 4 & 0.10 & 0.24 & 59 \\
\hline
\end{tabular}

Source: Authors' calculations.

When comparing the results we obtained with those from other countries (Tables A2a and A2b in the annexure), our results demonstrate lower levels of trust and trustworthiness than most previous studies. The results from our first round (which represents the participants' natural inclinations rather than learning) indicated that 35 percent of the endowment was sent by first movers (trustors) and 24 percent of the money received was returned by second movers (trustees) with a return ratio of 0.73 . These results are very similar to Burns' (2004) results in South Africa. Over all rounds, first movers sent money nearly 70 percent of the time, which is similar to the results obtained by Delavande and Zafar (2011) where 75 percent of first movers passed money.

\section{The Dictator Game}

The results of the dictator game experiment are presented in Tables $3 a$ and $3 b$. In the first round, participants contributed nearly one third of their endowments. Over all rounds, the average contribution was 20 percent of endowments, with men and women contributing nearly equally (Table 3a). There was some variation across sessions, with section 1 contributing a low of 16 percent and section 4 with a high of 24 percent of their endowment. 
Table 3a: Results of the Dictator Game

\begin{tabular}{lcc}
\hline Subsample & $\begin{array}{c}\text { Mean Allocation (Share } \\
\text { of Endowment) }\end{array}$ & No. of observations \\
\hline All & 0.20 & 238 \\
Women, men & $0.21,0.19$ & 134,104 \\
\hline Round 1 & 0.32 & 54 \\
Round 2 & 0.18 & 54 \\
Round 3 & 0.12 & 54 \\
Round 4 & 0.17 & 54 \\
\hline Section 1 & 0.16 & 75 \\
Section 2 & 0.21 & 76 \\
Section 3 & 0.21 & 52 \\
Section 4 & 0.24 & 35 \\
\hline
\end{tabular}

Source: Authors' calculations.

Over all rounds and across all sessions, in 47 percent of the interactions, the proposer gave nothing to the recipient (Table $3 b$ ). This figure rose over the rounds, since only 29 percent gave nothing in the first round. The share of men who gave nothing was somewhat higher than women (54 percent compared to 42 percent). There was also some clustering around an allocation of half the endowment (15 percent of observations overall, 20 percent in the first round of the game). Overall, less than 10 percent of observations represented a donation of more than half the endowment, down from 16 percent of participants in the first round of play.

Table 3b: Results of the Dictator Game (cont'd)

\begin{tabular}{lrrr}
\hline $\begin{array}{l}\text { Allocation (Share } \\
\text { of Endowment) }\end{array}$ & \multicolumn{1}{c}{ All } & Women & Men \\
\hline 0.0 & $47.06 \%$ & $42 \%$ & $54 \%$ \\
0.1 & 10.92 & 9.7 & 12.5 \\
0.2 & 8.82 & 13.4 & 2.9 \\
0.3 & 5.04 & 4.5 & 5.8 \\
0.4 & 5.88 & 8.2 & 2.9 \\
0.5 & 15.13 & 15.7 & 14.4 \\
0.6 & 2.10 & 1.5 & 2.9 \\
0.7 & 0.84 & 0.8 & 1.0 \\
0.8 & 0.84 & 0.8 & 1.0 \\
0.9 & 1.26 & 2.2 & 0.0 \\
1.0 & 2.10 & 1.5 & 2.9 \\
Observations & 238 & 134 & 104 \\
\hline
\end{tabular}

Source: Authors' calculations. 
Looking at previous studies' results for the dictator game (Tables $\mathrm{A} 3 \mathrm{a}$ and $\mathrm{A} 3 \mathrm{~b}$ in the annexure), we can see how the results differ significantly between students and nonstudents, with students offering significantly lower amounts to recipients. Across countries, the mean allocations for student subjects were clustered between 24 and 28 percent of the endowment. In that respect, the allocation of 35 percent obtained in our study was higher than what the average student gave, but lower than the average nonstudent allocation. One should recall, however, that actual money was not transacted in our game, which would likely bias the allocations in our study upward. In comparison, in Delavande and Zafar's (2011) study, students sent 43 percent of their endowment.

\section{The Ultimatum Game}

The results of the ultimatum game experiment can be found in Tables $4 \mathrm{a}$ and $4 \mathrm{~b}$. When the second mover has the option of rejecting the offer made by the first mover (compared to the dictator game where the second mover is silent), the mean offer rises to over 40 percent of the endowment (Table 4a). These results are consistent across rounds and across sessions. In most instances, between one quarter and one third of offers were rejected.

Table 4a: Results of the Ultimatum Game

\begin{tabular}{llll}
\hline Subsample & $\begin{array}{c}\text { Mean Allocation } \\
\text { (Share) }\end{array}$ & Rejection Rate & No. of observations \\
\hline All & 0.41 & 0.31 & 245 \\
Women, men & $0.43,0.38$ & $0.29,0.33$ & 136,109 \\
\hline Round 1 & 0.41 & 0.26 & 54 \\
Round 2 & 0.42 & 0.33 & 53 \\
Round 3 & 0.43 & 0.33 & 51 \\
Round 4 & 0.35 & 0.37 & 51 \\
\hline Section 1 & 0.38 & 0.28 & 69 \\
Section 2 & 0.40 & 0.28 & 89 \\
Section 3 & 0.44 & 0.42 & 52 \\
Section 4 & 0.45 & 0.26 & 35 \\
\hline
\end{tabular}

Source: Authors' calculations.

Over all observations, only one quarter of offers was less than 0.4 of the endowment. Two thirds of offers were 0.4 or half of the proposer's endowment. Fewer than 10 percent of proposers offered more than half their endowment (Table $4 b$ ). 
Table 4b: Results of the Ultimatum Game (cont'd)

\begin{tabular}{lrrr}
\hline Allocation & All & Women & Men \\
\hline 0.0 & $9 \%$ & $4.4 \%$ & $14.5 \%$ \\
0.1 & 2.5 & 1.5 & 3.7 \\
0.2 & 4.5 & 3.7 & 5.5 \\
0.3 & 9.0 & 7.4 & 11.0 \\
0.4 & 21.2 & 27.9 & 12.8 \\
0.5 & 46.5 & 48.5 & 44.0 \\
0.6 & 3.3 & 3.7 & 2.8 \\
0.7 & 1.2 & 1.5 & 0.9 \\
0.8 & 0.8 & 0.0 & 1.8 \\
0.9 & 0.0 & 0.0 & 0.0 \\
1.0 & 2.0 & 1.5 & 2.8 \\
Observations & 245 & 132 & 107 \\
\hline
\end{tabular}

Source: Authors' calculations.

Fewer than 10 percent of offers of half or more the endowment were rejected, whereas nearly 60 percent of offers of less than half the endowment were turned down (Table $4 \mathrm{c}$ ). The propensity to reject a proposal by the first mover rose fairly smoothly as the offers fell, demonstrating strong norms of fairness. Even offers of 0.4 of the endowment were rejected in almost half of the interactions. Nearly all offers of 0.0 or 0.1 were rejected. Surprisingly, a non-negligible share of offers of 0.5 and 0.6 were rejected; these may have been strategic moves since the game was repeated (with the same pairings of proposers and responders) over the multiple rounds.

Table 4c: Results of the Ultimatum Game (cont'd)

\begin{tabular}{lcccc}
\hline $\begin{array}{l}\text { Mean } \\
\text { Allocation }\end{array}$ & $\begin{array}{c}\text { Share of } \\
\text { Proposals }\end{array}$ & $\begin{array}{c}\text { Rejection } \\
\text { (All) }\end{array}$ & $\begin{array}{c}\text { Rejection } \\
\text { (Men) }\end{array}$ & $\begin{array}{c}\text { Rejection } \\
\text { (Women) }\end{array}$ \\
\hline 0.0 & $9 \%$ & $85.7 \%$ & $81.2 \%$ & $100 \%$ \\
0.1 & 2.5 & 83.3 & 75.0 & 100.0 \\
0.2 & 4.5 & 40.0 & 50.0 & 25.0 \\
0.3 & 9.0 & 59.0 & 58.3 & 60.0 \\
0.4 & 21.2 & 43.1 & 46.2 & 42.1 \\
0.5 & 46.5 & 8.9 & 4.2 & 12.5 \\
0.6 & 3.3 & 25.0 & 33.3 & 20.0 \\
0.7 & 1.2 & 0.0 & 0.0 & 0.0 \\
0.8 & 0.8 & 0.0 & 0.0 & - \\
0.9 & 0.0 & - & - & - \\
1.0 & 2.0 & 0.0 & 0.0 & 0.0 \\
\hline
\end{tabular}

Source: Authors' calculations. 
Comparing the results derived from our experimental sessions with previous studies, the mean offer we calculated was nearly identical to other studies with student subjects, and lies within the ranges of nonstudent subjects as well (Tables A4a and A4b in the annexure). The rejection rates in our study were somewhat higher than in other studies, but that may have been due in part to the lack of real money being exchanged in our experiments.

\section{Conclusions}

This paper has offered some preliminary evidence about pro-social behavior among a sample of students based in Lahore, Pakistan. The results indicate similar behaviors to other student subjects, particularly in the dictator and ultimatum games. Our student sample exhibited lower levels of trust and reciprocity compared to both other student and nonstudent populations. There were fewer cross-country observations on prisoner's dilemma games; however, the results obtained in the current study appeared comparable.

In our results, we observed the highest levels of pro-social behavior in the initial rounds with deterioration in subsequent rounds. We also observed variation across the sections in which the games were played. One group of students (out of four sections) was an outlier and demonstrated higher levels of pro-social behavior across the board. Women behaved similarly to men in the dictator and ultimatum games, but exhibited greater tendencies toward cooperation in the prisoner's dilemma game, but lower trust and trustworthiness in the trust game. As the games presented here were part of a classroom assignment, real

money was not exchanged, which is an important caveat in the interpretation of our results. 


\section{References}

Acemoglu, D., Johnson, S., \& Robinson, (2001). Colonial origins of comparative development: An empirical study. American Economic Review, 91(5): 1369-1401.

Andreoni, J., \& Miller, J. H. (1993). Rational cooperation in the finitely repeated prisoner s dilemma: Experimental evidence. The Economic Journal, 103(418), 570-585.

Ashraf, N., Bohnet, I., \& Piankov, N. (2006). Decomposing trust and trustworthiness. Experimental Economics, 9(3), 193-208

Berg, J., Dickhaut, J., \& McCabe, K. (1995). Trust, reciprocity, and social history. Games and Economic Behavior, 10(1), 122-142.

Bohnet, I., \& Frey, B. S. (1999). The sound of silence in prisoner's dilemma and dictator games. Journal of Economic Behavior \& Organization, 38(1), 43-57.

Buchan, N., Croson, R., Solnick, S.S.(2003). Trust and gender: an examination of behavior, biases, and beliefs in the Investment game. Working paper, University of Pennsylvania.

Buchan, N. R., Johnson, E. J., \& Croson, R. T. A. (2006). Let's get personal: An international examination of the influence of communication, culture and social distance on other regarding preferences. Journal of Economic Behavior E Organization, 60(3), 373-398

Burks, S., Carpenter, J. P., \& Verhoogen, E. (2003). Playing both roles in the trust game. Journal of Economic Behavior E Organization, 51(2), 195-216.

Cameron, L. A. (1999). Raising the stakes in the ultimatum game: Experimental evidence from Indonesia. Economic Inquiry, 37(1), 47-59.

Cardenas, J., \& Carpenter, J. (2008). Behavioral development economics: Lessons from field labs in the developing world. Journal of Development Studies, 44(3), 337-364.

Carpenter, J., Burks, S., \& Verhoogen, E. (2004). Comparing students to workers: The effects of social framing on behavior in distribution games. Field Experiments in Economics Research in Experimental Economics, 10(1341), 1-17 
Carter, M. R., \& Castillo, M. (2002). The Economic Impacts of Altruism, Trust and Reciprocity: An Experimental Approach to Social Capital. mimeo.

Cameror, C. (2003). Behavioral Game Theory. Princeton: Princeton University Press

Carter, J. R., \& Irons, M. D. (1991). Are Economists Different, and If So, Why? The Journal of Economic Perspectives, 5(2), 171-177

Cooper, R., DeJong, D. V., Forsythe, R., \& Ross, T. W. (1996). Cooperation without reputation: Experimental evidence from prisoner $\mathrm{s}$ dilemma games. Games and Economic Behavior, 12(2), 187-218

Cox, J., Friedman, D., \& Gjerstad, S. (2002). A tractable model of reciprocity and fairness. Working Paper, University of Arizona

Cox, J. (2004). How to identify trust and reciprocity. Games and Economic Behavior, 46(2), 260-281.

Delavande, A., \& Zafar, B. (2011). Stereotypes and madrassas: Experimental evidence from Pakistan (Staff Report No. 501). New York, NY: Federal Reserve Bank of New York.

Dufwenberg, M., \& Gneezy, U. (2000). Measuring Beliefs in an Experimental Lost Wallet Game. Games and Economic Behavior, 30(2), 163-182.

Eckel, R, C. C., \& Grossman, P. J. (1996). Altruism in Anonymous Dictator Games. Games and Economic Behavior, 16(2), 181-191.

Fehr, E., \& List, J. A. (2004). The Hidden Costs and Returns of IncentivesTrust and Trustworthiness Among CEOs. Journal of the European Economic Association, 2(5), 743-771.

Frank, R. H., \& Regan, D. T. (1993). Does Studying Economics Inhibit Cooperation. Journal of Economic Perspectives, 7(2), 159-171.

Forsythe, R., Horowitz, J. L., Savin, N. E., \& Sefton, M. (1994). Fairness in Simple Bargaining Games. Games and Economic Behavior, 6(3), 347-369

Glaeser, E. L., Laibson, D. I., Scheinkman, J. A., \& Soutter, C. L. (2000). Measuring Trust. Quarterly Journal of Economics, 115(3), 811-846. 
Gowdy, J., Iorgulescu, R., \& Onyeiwu, S. (2003). Fairness and retaliation in a rural Nigerian village. Journal of Economic Behavior and Organization, 52(4), 469-479.

Harbaugh, W., Krause, K., \& Vesterlund, L. (2001). Are adults better behaved than children? Age, experience, and the endowment effect. Economic Letters, 70(2), 175-181.

Harbaugh, W. T., Krause, K., Liday, S. G., \& Vesterlund, L. (2003). Trust in Children. Trust Reciprocity and Gains from Association Interdisciplinary Lessons from Experimental Research. 303-22. Russell Sage Foundation.

Hemesath, M., \& Pomponio, X. (1998). Cooperation and Culture: Students from China and the United States in a Prisoner s Dilemma. Cross Cultural Research, 32(2), 171-184.

Henrich, J., Boyd, R., Bowles, S., Camerer, C., Fehr, E., Gintis, H. and McElreath, R. (2001) In search of homo economics: Behavioral experiments in 15 small-scale societies. American Economic Review, 91(2), 73-78.

Henrich, J., McElreath, R., Barr, A., Ensminger, J., Barrett, C., Bolyanatz, A., Cardenas, J.C., Gurven, M., Gwako, E., Henrich, N., Lesorogol, C., Marlowe, F., Tracer, D. and Ziker, J. (2006) Costly punishment across human societies. Science, 312(23 June 2006), 1767-1770.

Hoffman, E., McCabe, K., Shachat, K., \& Smith, V. (1994). Preferences, property rights, and anonymity in bargaining games. Games and Economic Behavior, 7(3), 346-380.

Holm, H. and Danielson, A. (2005) Trust in the tropics? Experimental evidence from Tanzania. The Economic Journal, 115(503), 505-532.

Kahneman, D., Knetsch, J., \& Thaler, R. (1986). Fairness as a constraint on profit seeking: Entitlements in the market." American Economic Review, 76(4): 728-41.

Knack, S., \& Keefer, P. (1997). Does Social Capital Have An Economic Payoff? A Cross-Country Investigation. Quarterly Journal of Economics, 112(4), 1251-1288. 
Kreps, D. M., Milgrom, P., Roberts, J., \& Wilson, R. (1982). Rational Cooperation in the Finitely Dilemma Repeated Prisoners. Journal of Economic Theory, 27(2), 245-252.

Lazzarini, S., Madalozzo, R., Artes, R. and de Oliveira Siqueira, J. (2004) Measuring trust: An experiment in Brazil. Ibmec Working Paper WPE -2004 - 1.

Levitt, S., \& List, J. A. (2006). What do Laboratory Experiments Measuring Social Preferences tell us about the Real World. Journal of Economic Perspectives, 21(2), 153-174.

Murnighan, J. K., \& Saxon, M. S. (1998). Ultimatum bargaining by children and adults. Journal of Economic Psychology, 19(4), 415-445.

Rabin, M. (1993). Incorporating Fairness into Game Theory and Economics. American Economic Review, 83(5), 1281-1302.

Razzaque, S. (2009). The ultimatum game and gender effect: Experimental evidence from Pakistan. Pakistan Development Review, 48(1), 23-46. 
Annexure

Table A1: Prisoner's Dilemma Results from Other Countries (Student Subjects)

\begin{tabular}{lll}
\hline Study & Location & \multicolumn{1}{c}{ Mean Cooperation } \\
\hline Hemesath and Pomponio (1998) & China & $54 \%$ cooperate \\
Tyson et al. (1988) & South Africa & $45 \%$ cooperate w/black other \\
Tyson et al. (1988) & South Africa & $37 \%$ cooperate w/white other \\
Hemesath and Pomponio (1998) & United States & $25 \%$ cooperate \\
Cooper et al. (1996) & United States & $22 \%$ cooperate \\
\hline
\end{tabular}

Source: Cardenas and Carpenter (2008).

Table A2a: Trust Game Results from Other Countries (Student Subjects)

\begin{tabular}{llrrr}
\hline Study & Location & $\begin{array}{r}\text { Fraction } \\
\text { Sent }\end{array}$ & $\begin{array}{c}\text { Fraction } \\
\text { Returned }\end{array}$ & $\begin{array}{c}\text { Return } \\
\text { Ratio }\end{array}$ \\
\hline Buchan et al. (2003) & China & 0.73 & $0.50 \mathrm{a}$ & 1.51 \\
Buchan et al. (2003) & Japan & 0.68 & $0.50 \mathrm{a}$ & 1.51 \\
Burks et al. (2003) & United States & 0.65 & 0.40 & 1.31 \\
Buchan et al. (2003) & United States & 0.65 & $0.45 \mathrm{a}$ & 1.35 \\
Buchan et al. (2003) & South Korea & 0.64 & $0.49 \mathrm{a}$ & 1.47 \\
Koford (2001) & Bulgaria & 0.63 & 0.46 & 1.34 \\
Lazzarini et al. (2004) & Brazil & 0.56 & 0.34 & 0.80 \\
Holm and Danielson & Tanzania & 0.53 & 0.37 & 1.17 \\
(2005) & & & & \\
Berg et al. (1995) & United States & 0.52 & 0.30 & 0.90 \\
Holm and Danielson & Sweden & 0.51 & 0.35 & 1.05 \\
(2005) & & & & \\
Cardenas (2003b) & Colombia & 0.50 & 0.41 & 1.22 \\
Ashraf et al. (2005a) & Russia & 0.49 & 0.29 & 0.80 \\
Ashraf et al. (2005a) & South Africa & 0.43 & 0.27 & 0.73 \\
Ashraf et al. (2005a) & United States & 0.41 & 0.23 & 0.58 \\
Fehr and List (2004) & Costa Rica & 0.40 & 0.32 & 0.96 \\
Burns (2004b) & South Africa & 0.33 & 0.23 & 0.70 \\
\hline
\end{tabular}

Source: Cardenas and Carpenter (2008). 
Table A2b: Trust Game Results from Other Countries (Nonstudent Subjects)

\begin{tabular}{llrrr}
\hline Study & Location & $\begin{array}{c}\text { Fraction } \\
\text { Sent }\end{array}$ & $\begin{array}{c}\text { Fraction } \\
\text { Returned }\end{array}$ & $\begin{array}{c}\text { Return } \\
\text { Ratio }\end{array}$ \\
\hline Fehr and List (2004) & Costa Rica & 0.59 & 0.44 & 1.32 \\
Danielson and Holm (2003) & Tanzania & 0.56 & 0.46 & 1.40 \\
Carter and Castillo (2002) & South Africa & 0.53 & 0.38 & 1.14 \\
Wilson and Bahry (2002) & Russia & 0.51 & 0.38 & 1.15 \\
Castillo and Carter (2003) & Honduras & 0.49 & 0.42 & 1.26 \\
Mosley and Verschoor (2003) & Uganda & 0.49 & 0.33 & 0.99 \\
Schechter (2004) & Paraguay & 0.47 & 0.44 & 1.31 \\
Johansson-Stenman et al. & Bangladesh & 0.46 & 0.46 & 1.38 \\
(2004) & & & & \\
Karlan (2005) & Peru & 0.46 & 0.43 & 1.12 \\
Ensminger (2000) & Kenya & 0.44 & 0.18 & 0.54 \\
Barr (2003a) & Zimbabwe & 0.43 & 0.43 & 1.28 \\
Greig and Bohnet (2005) & Kenya & 0.30 & 0.41 & 0.82 \\
\hline
\end{tabular}

Source: Cardenas and Carpenter (2008).

Table A3a: Dictator Game Results from Other Countries (Student Subjects)

\begin{tabular}{llc}
\hline Study & \multicolumn{1}{c}{ Location } & Mean Allocation \\
\hline Henrich et al. (2006) & United States & 0.32 \\
Holm and Danielson (2005) & Sweden & 0.28 \\
Cardenas and Carpenter (2004) & United States & 0.27 \\
Ashraf et al. (2005) & Russia & 0.26 \\
Burns (2004) & South Africa & 0.26 \\
Carpenter et al. (2005) & United States & 0.25 \\
Ashraf et al. (2005) & South Africa & 0.25 \\
Ashraf et al. (2005) & United States & 0.24 \\
Holm and Danielson (2005) & Tanzania & 0.24 \\
Cardenas and Carpenter (2004) & Colombia & 0.19 \\
\hline
\end{tabular}

Source: Cardenas and Carpenter (2008). 
Table A3b: Dictator Game Results from Other Countries (Nonstudent Subjects)

\begin{tabular}{llc}
\hline Study & \multicolumn{1}{c}{ Location } & Mean Allocation \\
\hline Henrich et al. (2006) & United States & 0.47 \\
Carpenter et al. (2005a) & United States & 0.45 \\
Henrich et al. (2006) & Colombia (Sanquianga) & 0.44 \\
Henrich et al. (2006) & Ghana (Accra City) & 0.42 \\
Carter and Castillo (2002) & South Africa & 0.42 \\
Castillo and Carter (2003) & Honduras & 0.42 \\
Gowdy et al. (2003) & Nigeria & 0.42 \\
Henrich et al. (2006) & Papua New Guinea (Au, & 0.41 \\
& Sursurunga) & \\
Henrich et al. (2006) & Kenya (Samburu) & 0.40 \\
Henrich et al. (2006) & Siberia (Dolgan) & 0.37 \\
Henrich et al. (2006) & Tanzania (Isanga) & 0.36 \\
Henrich et al. (2006) & Kenya (Maragoli) & 0.35 \\
Henrich et al. (2006) & Fiji (Yasawa) & 0.35 \\
Henrich et al. (2006) & Ecuador (Shuar) & 0.35 \\
Henrich et al. (2006) & Kenya (Gusii) & 0.33 \\
Ensminger (2000) & Kenya & 0.31 \\
Henrich et al. (2006) & Tanzania (Hadza) & 0.26 \\
Henrich et al. (2006) & Bolivia (Tsimane) & 0.26 \\
\hline
\end{tabular}

Source: Cardenas and Carpenter (2008).

Table A4a: Ultimatum Game Results from Other Countries - Student Subjects

\begin{tabular}{llcc}
\hline Study & Location & $\begin{array}{c}\text { Mean } \\
\text { Proposal }\end{array}$ & Rejection Rate \\
\hline Carpenter et al. (2005a) & United States & 0.41 & 0.05 \\
Cameron (1999) & Indonesia & 0.42 & 0.10 \\
Henrich et al. (2006) & United States & 0.41 & $0.42 \mathrm{~b}$ \\
\hline
\end{tabular}

Source: Cardenas and Carpenter (2008).

b Strategy method used so we report the probability that the lowest positive offer (10 percent) would be rejected. 


\section{Table A4b: Ultimatum Game Results from Other Countries (Nonstudent Subjects)}

\begin{tabular}{|c|c|c|c|}
\hline Study & Location & $\begin{array}{c}\text { Mean } \\
\text { Proposal }\end{array}$ & $\begin{array}{c}\text { Rejection } \\
\text { Rate }\end{array}$ \\
\hline Henrich et al. (2001) & Indonesia (Lamelara) & 0.58 & 0.00 \\
\hline Henrich et al. (2001) & Paraguay (Ache) & 0.51 & 0.00 \\
\hline Henrich et al. (2006) & $\begin{array}{l}\text { Papua New Guinea } \\
\text { (Sursurunga) }\end{array}$ & 0.51 & $0.69 b$ \\
\hline Henrich et al. (2006) & United States & 0.48 & $0.71 b$ \\
\hline Henrich et al. (2006) & Colombia (Sanquianga) & 0.48 & $0.30 \mathrm{~b}$ \\
\hline Carpenter et al. (2005a) & United States & 0.45 & 0.07 \\
\hline Henrich et al. (2001) & Kenya (Orma) & 0.44 & 0.04 \\
\hline Henrich et al. (2006) & Ghana (Accra City) & 0.44 & $0.33 b$ \\
\hline Henrich et al. (2006) & Papua New Guinea $(\mathrm{Au})$ & 0.44 & $0.43 b$ \\
\hline Gowdy et al. (2003) & Nigeria & 0.43 & 0.01 \\
\hline Henrich et al. (2006) & Siberia (Dolgan) & 0.43 & $0.35 b$ \\
\hline Henrich et al. (2001) & Ecuador (Achuar) & 0.42 & 0.00 \\
\hline Henrich et al. (2001) & Zimbabwe & $0.41,0.45$ & $0.10,0.07$ \\
\hline Henrich et al. (2001) & Tanzania (Sangu) & $0.41,0.42$ & $0.25,0.05$ \\
\hline Henrich et al. (2006) & Kenya (Gusii) & 0.4 & NA \\
\hline Henrich et al. (2006) & Fiji (Yasawa) & 0.4 & $0.15 b$ \\
\hline Henrich et al. (2001) & Papua New Guinea $(\mathrm{Au})$ & $0.43,0.38$ & $0.27,0.40$ \\
\hline Henrich et al. (2006) & Tanzania (Isanga) & 0.38 & $0.10 \mathrm{~b}$ \\
\hline Henrich et al. (2001) & Bolivia (Tsimane) & 0.37 & 0.00 \\
\hline Henrich et al. (2006) & Ecuador (Shuar) & 0.37 & $0.10 \mathrm{~b}$ \\
\hline Henrich et al. (2001) & Mongolia (Torguud) & $0.35,0.36$ & $0.05, \mathrm{a}$ \\
\hline Henrich et al. (2006) & Kenya (Samburu) & 0.35 & $0.10 \mathrm{~b}$ \\
\hline Henrich et al. (2001) & Chile (Mapuche) & 0.34 & 0.07 \\
\hline Henrich et al. (2001) & Tanzania (Hadza) & $0.40,0.27$ & $0.19,0.28$ \\
\hline Henrich et al. (2001) & Ecuador (Quichua) & 0.27 & 0.15 \\
\hline Henrich et al. (2006) & Bolivia (Tsimane) & 0.27 & $0.03 b$ \\
\hline Henrich et al. (2001) & Peru (Machiguenga) & 0.26 & 0.05 \\
\hline Henrich et al. (2006) & Tanzania (Hadza) & 0.26 & $0.42 b$ \\
\hline Henrich et al. (2006) & Kenya (Maragoli) & 0.25 & $0.96 b$ \\
\hline
\end{tabular}

Source: Cardenas and Carpenter (2008).

b Strategy method used so we report the probability that the lowest positive offer (10 percent) would be rejected. 